\title{
Controle e prevenção da calcinose branca em Bombyx mori L. (Lepidoptera: Bombycidae)
}

\author{
Control and prevention of white muscardine in \\ Bombyx mori L. (Lepidoptera: Bombycidae)
}

\section{Rafaela Barbosa Pares ${ }^{1}$, Luis Francisco Angeli Alves 1*}

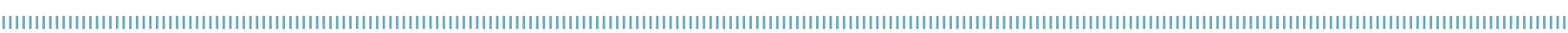

RESUMO: Um dos principais problemas enfrentados pelos sericicultores em todo o mundo são entomopatógenos que causam grandes perdas na produçáo. Destaca-se a doença calcinose branca, causada pelo fungo Beauveria bassiana (Bals.) Vuill. (Ascomycota: Cordycipitaceae). Doenças fúngicas são facilmente disseminadas, já que os conídios são transportados pelo ar. Além disso, as condições de temperatura e umidade nos barracóes são favoráveis ao surgimento e à manutençáo do fungo, aumentando sua incidência. Práticas de higiene como a desinfecção do barracão e de utensílios são recomendadas, no entanto a contaminação das lagartas ainda é frequente. Dessa forma, esse artigo reuniu trabalhos voltados para a pesquisa de produtos antimicrobianos alternativos para o uso em sericicultura.

PALAVRAS-CHAVE: bicho-da-seda; Beauveria bassiana; sericicultura.
ABSTRACT: Entomopathogens are the most important problem from sericulture all over the world, and cause heavy loss to silkworm crops. Calcinosis is a common disease of silkworm, caused by the pathogenic fungus Beauveria bassiana (Bals.) Vuill. (Ascomycota: Cordycipitaceae). Fungal diseases of silkworm are easily spread by spores which are carried through the air. Also, temperature and humidity inside the silkworm rearing rooms are favorable to disease development. Practice hygiene measures during silkworm rearing such as disinfection of rearing houses and appliances are recommended. However, contamination is frequent. This paper presents related research on promising antimicrobiotic products for their use in sericulture industry.

KEYWORDS: silkworm; Beauveria bassiana; sericulture. 


\section{INTRODUÇÃO}

A sericicultura surgiu na China há cerca de 4.600 anos, visando à produçáo de fios de seda pelo bicho-da-seda (Bombyx mori L.) (Lepidoptera: Bombycidae). A partir de então, B. mori é a principal espécie criada comercialmente com vistas à produção de fios de seda (Gallo et al., 2002).

Por conta das condições climáticas do Brasil, a sericicultura adaptou-se com grande sucesso no país, sendo possível a produçáo de sete a nove lotes por ano, enquanto no Japão a média de produção é de três ou quatro. A alimentação da lagarta é composta exclusivamente por folhas de amoreira, uma planta bastante rústica e de fácil cultivo, o que garante o sucesso da atividade sericícola (Amaral; Alves, 1979).

Nos dias atuais, a sericicultura tem sido um meio de subsistência econômica para muitos trabalhadores do campo e da cidade (KuRIN, 2002). No Brasil, a produção está concentrada nas pequenas propriedades rurais, onde predomina o trabalho familiar, envolvendo aproximadamente 4.500 famílias de sericicultores integradas ao processo de produção de casulo, o que gera em torno de 20 mil empregos indiretos no ramo (EsTADo DO Paraná; SEAB; DERAL, 2013; Vale da Seda, 2010). O Brasil é o quarto maior produtor de casulos verdes, ficando atrás da China, da Índia e do Uzbequistáo (InTERnational Sericultural Commission, 2013). O Paraná destaca-se como o estado que mais produz casulos verdes no Brasil e todos os anos contribui com cerca de $90 \%$ de toda a produção brasileira, sendo a maior parte destinada à exportação (Estado do Paraná, 2013).

A criação de $B$. mori caracteriza-se pela simplicidade de suas instalaçôes. São necessárias três construçôes básicas: a chocadeira, o barracáo de criaçáo propriamente dito e o depósito de ramos de amoreira. As chocadeiras pertencem às empresas de fiação, que, além de fornecerem as lagartas, também produzem mudas de amoreira que sáo repassadas ao produtor. A fase larval desde a eclosão do ovo até o encasulamento compreende em média 27 dias, divididos em cinco ínstares, período no qual a lagarta se alimenta exclusivamente de folhas de amoreira (CORRADELLO, 1987).

A temperatura é fator limitante para a produção de seda por B. mori. Entre 20 e $30^{\circ} \mathrm{C}$, considera-se a temperatura adequada para o desenvolvimento. Fora dessa faixa, a lagarta diminui sua alimentação, chegando a interrompê-la abaixo de $13^{\circ} \mathrm{C}$ e acima de $35^{\circ} \mathrm{C}$. A umidade adequada fica em torno de 80\% (Secretaria da Agricultura e do Abastecimento, 2005; Hussain et al., 2011).

\section{PROBLEMAS ASSOCIADOS À CRIAÇÃO DE B. MORI}

A simplicidade e a pouca tecnologia nos barracóes fazem da sericicultura uma atividade propensa a surtos de micro-organismos que podem comprometer todo o lote de criaçáo.
Fatores abióticos do ambiente de criação, como temperatura, luminosidade e umidade, são favoráveis ao inseto e também ao desenvolvimento de entomopatógenos. Também, do ponto de vista biótico, destacam-se fatores como a alta suscetibilidade das lagartas aos entomopatógenos, a grande concentração de lagartas em ambiente fechado, a alta produção de resíduos orgânicos, um ciclo biológico curto que limita o tempo de combate à doença e a ausência do controle dos entomopatógenos presentes nos ramos de amoreira (PORTO et al., 2005).

Os entomopatógenos que acometem as lagartas do bicho-da-seda, em todos os ínstares, são protozoários, bactérias, fungos e vírus, com destaque para os dois últimos (РотRich et al., 2007). Estima-se que na Índia a perda por conta de doenças em $B$ mori é de 30\% (Selvakumar et al., 2002). Para tanto, medidas preventivas e/ou curativas são adotadas na prevenção/no controle das doenças causadas por esses micro-organismos (BrancalHâo, 2002; ZANETTI, 2011a).

Outro problema encontrado pelos criadores é a intoxicação dos insetos por inseticidas químicos, empregados em lavouras localizadas nas proximidades das áreas de criação e de coleta de folhas de amora e que acabam por contaminar os insetos, já que a pulverização aérea ou terrestre dessas culturas pode atingir o amoreiral e causar prejuízos aos criadores do inseto (Hanada; Watanabe, 1986; Nasr, 2011). Na China, também são relatadas perdas na produção em decorrência de intoxicação das lagartas por inseticidas, com prejuízos que podem chegar a 30\% anualmente. Não apenas as aplicaçôes em culturas vizinhas preocupam os produtores, mas os próprios inseticidas utilizados no amoreiral podem intoxicar as lagartas, sendo também alvo de estudos (BING et al., 2010).

Nesse sentido, no Paraná, um inseticida do grupo químico das antranilamidas, cujo princípio ativo é o Chlorantraniliprole, preocupou os produtores há alguns anos, já que é registrado para diversas culturas, entre elas soja e algodáo. Por agir pela sua ingestão, ligando-se aos receptores de rianodina dos insetos, afeta diretamente a funçáo muscular (CoRdova et al., 2006). Em experimentos em laboratório, lagartas de B. mori foram tratadas com Chlorantraniliprole e foram observados sintomas como parada de alimentaçáo, vômito, desenvolvimento e ecdise irregular. Além disso, conforme a concentração do inseticida se elevou, também houve diminuição de produçáo de casulos e aqueles que chegaram a ser produzidos apresentavam o córion mais fino (MunHoz et al., 2012; Pereira et al., 2012).

\section{ENTOMOPATÓGENOS QUE ACOMETEM A CRIAÇÃO DE B. MORI}

A principal causa das perdas em sericicultura é atribuída a doenças virais. $\mathrm{O}$ vírus da poliedrose nuclear (NPV) possui 
corpos de inclusão poliédrica denominados de poliedros e contêm vários vírions. Os corpos de oclusóes virais permitem aos nucleopolyhedrovirus resistirem a condiçóes ambientais fora do hospedeiro. Sua transmissão é via oral, por meio da ingestão de folhas infectadas. Geralmente, oscilaçōes de temperatura, alimentação com folhas de má qualidade e irregularidade nos horários de alimentaçâo podem favorecer a maior incidência da virose (Hanada; Watanabe, 1986). Um vírus do gênero Alphabaculovirus chamado de nucleopolyhedrovirus, subgrupo múltiplo de B. mori (BmMNPV), foi isolado no estado do Paraná e apresenta-se altamente patogênico, em função da presença de vários nucleocapsídeos por vírion e elevada mortalidade em curto espaço de tempo (BranCalHấo et al., 2002; TORQUato et al., 2006).

$\mathrm{O}$ ciclo de infecção do vírus começa quando o inseto se alimenta das folhas de amoreira (Morus alba), contendo poliedros. Os insetos infectados diminuem a alimentaçáo e retardam o crescimento. $\mathrm{Na}$ fase tardia da infecção, o inseto torna-se flácido e, ao morrer, o seu tegumento se rompe facilmente, liberando grande quantidade de poliedros no ambiente (Hanada; Watanabe, 1986).

As doenças fúngicas, conhecidas como calcinose e aspergilose, diferentemente das virais, propagam-se pelo contato, e não por via oral. As condiçôes de umidade em torno de $70 \%$ e temperatura próxima de $25^{\circ} \mathrm{C}$ nos barracóes, as quais são favoráveis aos insetos, também propiciam a ocorrência da doença (Amaral; Alves, 1979; Hanada; Watanabe, 1986; Kumar, et al., 1999).

Os sintomas não costumam aparecer nos primeiros dias da infecção, mas sim após quatro ou cinco dias, quando as lagartas começam a rejeitar o alimento, têm dificuldades de locomoção e de fixação, o corpo fica flácido e encolhido, apresentando manchas na superfície que representam o local de penetraçáo do fungo. Após a morte do inseto, ocorre a colonizaçáo do cadáver e a extrusão do patógeno com produção de conídios que são facilmente transportados pelo vento e atingem novas lagartas (Amaral; Alves, 1979; Hanada; Watanabe, 1986). Além disso, os conídios desse fungo são capazes de germinar em qualquer região da cutícula, por onde penetram até atingir a hemocele e passam a crescer e se multiplicar (ALves, 1998).

Não obstante, os fatores ambientais, como temperatura e umidade, já mencionados anteriormente, as condições nutricionais e a própria suscetibilidade do hospedeiro influenciam no processo de germinação dos conídios (Alves, 1998).

A calcinose branca, principal doença fúngica relacionada à B. mori, é causada pelo fungo Beauveria bassiana Bals. (Vuill.), ao qual a lagarta é suscetível, principalmente nos primeiros ínstares (Amaral; Alves, 1979; Hanada; Watanabe, 1986; Kumar et al., 1999). No local de penetração do fungo no tegumento da lagarta, é possível observar a formação de um halo ao redor. A colonizaçáo da hemocele pelas hifas forma um complexo micelial e leva à morte da lagarta em cinco ou seis dias. Depois, passa a atingir outros tecidos e, por fim, emite hifas aéreas em seis dias pós-infecção (Kumar et al., 1999). Na Índia, essa é a principal doença fúngica que acomete as criaçôes de $B$. mori, com maior incidência em períodos chuvosos e no inverno (Selvakumar et al., 2002; Nataraju; Chandrasekharan, 2008).

Outra doença de importância é a bacteriana, causada por Bacillus thuringiensis Berliner. Essa bactéria possui esporo e cristal que são disseminados amplamente na criação e infecta o inseto oralmente. Por sua vez, a pebrina, doença provocada pelo protozoário Nosema bombycis (Näg. 1857), é transmitida aos ovos pela mariposa fêmea è̀s lagartas por via oral de folhas infestadas (ZANETTI, 2011a).

Especificamente no Paraná, РотRIch et al. (2007) analisaram amostras de lagartas doentes de 139 barracôes de criação nas regióes produtoras do estado e foi observada a maior incidência de baculovírus (31,4\% das amostras analisadas), seguida de infecção fúngica, estando presentes apenas B. bassiana (5,3\%) e por último $B$. thuringiensis (2,2\% dos infectados).

Posteriormente, Margatho et al. (2012) realizaram um estudo para avaliar a contaminaçấo fúngica e bacteriana nas chocadeiras da unidade de pesquisa e desenvolvimento de Gália, estado de São Paulo, antes de receber as lagartas e durante a criação, obtendo amostras da superfície de lagartas, paredes, piso, folhas de amoreira e picadeira de folhas, além da exposiçáo ao ar. A presença de fungos foi verificada em maior índice no piso, na picadeira de folhas, nas folhas de amoreira e nas lagartas. As bactérias foram encontradas em maior número no piso e nas folhas de amoreira, e as enterobactérias, apenas nas folhas de amoreira.

\section{MEDIDAS PREVENTIVAS E DE CONTROLE DE SURTOS DE DOENÇAS EM B. MORI}

Medidas preventivas nos barracóes de criação justificam-se, dada a suscetibilidade dos insetos, e são úteis para evitar contaminação. Nesse sentido, PARRA (1991) ressaltou a importância de pesquisas voltadas à descoberta de antimicrobianos destinados ao controle de micro-organismos patogênicos na criação de insetos. A desinfecção prévia do local é de suma importância, uma vez que os patógenos se alojam nos locais de criação e equipamentos (BrancalHão, 2002).

Sendo assim, antes do alojamento e após a retirada de cada lote de lagartas criado, recomenda-se a desinfecçáo com soluçáo de formol a 3\% pulverizada no local e em todos os equipamentos utilizados. Além disso, nos barracóes deve ser feita a aplicação de cal no piso antes de iniciar a criação (Hanada; Watanabe, 1986; Zanetti, 2011b). Salienta-se que mesmo na ausência das lagartas, e com todas as medidas de desinfecção do local e utensílios, ainda há contaminação por micro-organismos, porém em menores índices, afirma Margatho et al. (2012). 
Em relação ao controle de surtos de doenças nos barracôes, a primeira providência é a eliminação dos focos com a retirada das lagartas doentes da cama de criação. Em seguida, faz-se a aplicação de desinfetantes sobre as lagartas restantes, sendo mais empregados o Chlorothalonil a $2 \%$, o hipoclorito de cálcio a 3,5\%, a cal hidratada e o formol em pó. Os resíduos retirados devem ser queimados e deve ser feita a desinfecção habitual do barracão ao fim do lote (ZANETTi, 2011a).

Apesar de existirem e de serem adotadas, as medidas preventivas usadas nos barracóes para o controle das doenças que atacam a lagarta reduzem a infestação de micro-organismos, mas são ineficientes e podem apresentar restriçóes no seu uso, por conta do risco de intoxicação das lagartas e dos produtores (Surenda; Surenda, 1999).

O formol é um líquido tóxico, corrosivo e carcinogênico e pode ser rapidamente absorvido pelas vias respiratórias, pelo trato gastrointestinal e, com menor frequência, pela pele, causando dermatites de contato (SuperquímicA, 2011). O cloro também é altamente tóxico e corrosivo na presença de umidade, agindo sobretudo nos olhos e no sistema respiratório (Gama Gases, 2007). Já a cal hidratada apresenta riscos de irritação se entrar em contato com pele, olhos, boca, garganta e vias aéreas superiores (SuPERQuímicA, 2010).

Além disso, Surendra; Surendra (1999) argumentaram que o uso sistemático desses produtos por um longo período pode levar ao desenvolvimento de resistência pelos patógenos.

\section{MÉTODOS ALTERNATIVOS PARA O CONTROLE DE MICRO-ORGANISMOS EM B. MORI}

Considerando a problemática dos entomopatógenos nos barracôes de criação de $B$. mori e a ineficiência dos produtos convencionais utilizados na prática, são necessárias alternativas para essa situação que envolvam produtos seguros e eficazes. Contudo, o uso de um produto visando à prevenção e/ou ao controle de doenças nas sirgarias deve ser precedido do conhecimento da segurança desse produto para a lagarta de B. mori, seja para o seu desenvolvimento, seja para a produçáo da seda.

Assim, diversos estudos vêm sendo conduzidos, com vistas a avaliar produtos alternativos com propriedades antimicrobianas, como medida de controle e prevenção dessas doenças.

\section{FUNGICIDAS SINTÉTICOS}

Na tentativa de controlar a calcisone branca em B. mori, Corso; Moscardi (1981) avaliaram a eficiência dos fungicidas de uso agrícola Benomyl, Cerconil, Maneb, Daconil e Neantina. A suspensão fúngica foi pulverizada sobre folhas de amoreira.
Em seguida, as lagartas de B. mori foram postas a se alimentar, e tanto as folhas quanto as lagartas foram pulverizadas com os fungicidas. Observou-se que em todos os tratamentos houve redução da mortalidade causada por $B$. bassiana.

López; Bustillo (1993) avaliaram o efeito dos fungicidas Triadimefon, Cyproconazol e Benomyl, também para o controle da calcinose branca. Inicialmente, aplicaram-se os produtos sobre as folhas de amoreira que serviram de alimento para B. mori e em outro grupo, sobre o tegumento da lagarta, sendo observada a ausência de efeitos acerca de aspectos da biologia e da qualidade do casulo produzido por B. mori. Posteriormente, as lagartas foram infectadas com suspensão fúngica e tratadas com os fungicidas, também por intermédio de dois métodos: sobre as folhas e sobre o tegumento das lagartas. Verificou-se que o produto Triadimefon reduziu em $8 \%$ a mortalidade das lagartas infectadas com o fungo.

Depois, em função da utilização do fungicida Carbendazim na cultura de amoreira, BizhanNia et al. (2005) estudaram os efeitos desse fungicida no tocante a parâmetros da biologia de produção de $B$. mori. Quanto à mortalidade, não houve diferença estatística em comparação à testemunha. Já com relação ao peso, os tratamentos com o fungicida diminuíram o peso das larvas, bem como dos casulos produzidos, porém isso não afetou a produção de seda. Também foi constatado efeito negativo sobre o número de ovos, mas a viabilidade deles não foi afetada.

Kumar et al. (2011) demonstraram a eficácia dos fungicidas de uso agrícola Bavistin, Bayleton, Dithane M45 e Thiram, no controle da doença fúngica causada por Penicillium citrinum em Antheraea mylitta, espécie selvagem do bicho-da-seda. Os produtos testados foram aplicados sobre as folhas de Terminalia arjuna que servem de alimento para o inseto, resultando na redução de 49 a 94\% de mortalidade pelo patógeno.

\section{PRODUTOS FITOSSANITÁRIOS ALTERNATIVOS}

Experimentos de compatibilidade entre produtos fitossanitários alternativos e micro-organismos entomopatogênicos (entre os quais estáo fungos e bactérias entomopatogênicos) vêm sendo desenvolvidos, demonstrando que alguns desses produtos podem afetar parâmetros biológicos dos patógenos e dessa maneira vir a ser uma alternativa de controle ou prevenção da incidência de doenças em barracóes de criação de B. mori (Formentini et al., 2009; Mertz et al., 2010; MAMprim et al., 2014). Contudo, tais trabalhos tratam apenas da classificação dos produtos entre compatíveis e incompatíveis com os fungos entomopatogênicos, e, no âmbito de se descobrir novos produtos que possam ser utilizados com segurança na sericicultura, devem ser realizados estudos sobre a interaçáo de tais produtos com o bicho-da-seda. 
Dessa forma, PARES (2014) avaliou o potencial fungicida dos produtos fitossanitários alternativos Biogermex ${ }^{\circledR}$, Agro-Mos, Soil-Set e Planta Clean. Os produtos foram testados de duas formas: aplicados sobre as folhas de amoreira que serviram de alimento para as lagartas e sobre a própria lagarta. Ainda, avaliaram-se os produtos quanto à frequência de administração: uma única aplicação após a infecção com fungo e por quatro dias com uma administração diária. Foi observada diminuição da mortalidade de 25\% nas lagartas que foram pulverizadas com o produto Biogermex ${ }^{\circledR}$ apenas uma vez depois da infecção com o fungo e 26,7\% nas lagartas que foram pulverizadas por quatro dias.

\section{DESINFETANTES SINTÉTICOS}

Uma das alternativas são os desinfetantes e, entre eles, destaca-se um produto à base de cloreto de didecildimetilamônio. Esse princípio ativo possui propriedades bactericida, fungicida e viricida. $\mathrm{O}$ produto foi aplicado nas folhas de amoreira e diretamente no corpo da lagarta, em três concentraçóes distintas: $1 \mathrm{~mL}$ do produto/1.000 mL de água, $1 \mathrm{~mL} / 550 \mathrm{~mL}$ e $1 \mathrm{~mL} / 100 \mathrm{~mL}$. Foi verificado que na menor concentração o desinfetante não trouxe efeitos nocivos, nem para a lagarta nem para o casulo produzido (Porto; Окамото, 2000).

Recentemente, outro produto à base de dicloroisocianurato de sódio foi testado visando à inativação do nucleopoliedrovirus (NPVBm) em B. mori. O produto é um desinfetante empregado na limpeza de galpóes e equipamentos de aviários, náo sendo tóxico às aves ou ao meio ambiente. $\mathrm{O}$ desinfetante foi testado por intermédio da ingestão de folhas contendo NPVBm e tratadas com o produto, porém viu-se que o desinfetante não inativa o vírus e, ainda, exerce efeito negativo sobre a resistência do inseto (BrancAlHâo et al., 2013).

Por fim, Rajagopal et al. (2014) testaram o efeito do desinfetante Kavach (produto à base de clorotalonil) para o controle da calcinose branca em B. mori. Diversas concentraçôes foram testadas em duas linhagens diferentes, uma bivoltina e uma híbrida. Características biológicas e produtivas do bicho-da-seda foram avaliadas. Constatou-se que em concentraçóes mais altas do desinfetante Kavach (1,6\%) houve maior taxa de sobrevivência para ambas as linhagens, sendo $61,15 \%$ para a bivoltina e $63,10 \%$ para a híbrida.

\section{EXTRATOS VEGETAIS E PRODUTOS BIOLÓGICOS}

Extratos vegetais são reconhecidos por apresentarem inibidores naturais a determinados micro-organismos e são produtos do metabolismo secundário das plantas. Nesse sentido, especificamente em relaçáo ao controle de doenças do bicho-da-seda, o extrato da planta maravilha, Mirabilis jalapa, foi testado para o controle de doença viral. As lagartas foram previamente infectadas oralmente com NPVBm, por meio de folhas contaminadas, e os tratamentos com o extrato da planta seguiram de duas maneiras: em um grupo, o extrato foi aplicado diretamente sobre o corpo do inseto, e outro grupo recebeu folhas de amoreira tratadas com o extrato da planta. Em ambas as situaçóes, utilizaram-se três concentraçôes de extrato, sendo elas 5, 10 e 20\%. Os autores observaram que as lagartas tratadas com 5 e $10 \%$ do extrato obtiveram entre 90 e $100 \%$ de proteção contra a infecção pelo NPVBm. Já no grupo tratado com 20\%, houve parada da alimentação (Porto et al., 2005).

Extratos de Argemone mexicana, Terminalia arjuna, Syzygium cumini e Annona squamosa, plantas com conhecidas propriedades antifúngicas, foram avaliadas para o controle da calcinose branca em B. mori. O experimento foi conduzido mediante a pulverização da suspensão fúngica seguida da aplicação dos extratos vegetais. As lagartas receberam a pulverização com os extratos ao longo de três dias após a infecção, e os resultados mostraram que os extratos testados suprimiram a formação de esporos, reduziram a mortalidade e aumentaram a taxa de encasulamento (CHAvAN et al., 2011).

Por meio da seleção in vitro de extratos de plantas medicinais, constatou-se o potencial do extrato aquoso a 5\% de Allium sativum contra o fungo $B$. bassiana. Posteriormente, lagartas de B. mori foram infectadas topicamente com o fungo na concentração 1,8 $\times 10^{6}$ conídios/mL e, em seguida, foram pulverizadas todos os dias com o extrato, registrando sobrevivência até $53 \%$ contra $0 \%$ a testemunha (sem tratamento com extrato aquoso de $A$. sativum). Ao mesmo tempo, como medida preventiva, lagartas de $B$. mori foram postas sobre superfície contaminada com o fungo e após 30 minutos receberam a pulverização com o extrato e também após cada ecdise, garantindo sobrevivência de até $61 \%$ contra 4,6\% no controle. Observou-se ainda que o extrato de planta é absolutamente inofensivo para as lagartas de B. mori (Mohanan et al., 2007).

Também, IsAIARASU et al. (2011) comprovaram in vitro a eficiência de extratos aquosos e alcoólicos dos vegetais Acalypha indica, Ocimum sanctum e Tridax procumbens como alternativas para o controle das doenças bacterianas e fúngicas nas criaçóes de B. mori.

A quitosana, um princípio ativo extraído do exoesqueleto de crustáceos, foi avaliada em diferentes concentrações sobre o desenvolvimento in vitro de colônias de Serratia marcescens e no desenvolvimento da doença em lagartas de B. mori, oferecendo folhas de amoreira tratadas com as soluçóes. Foi verificada a ação positiva da quitosana na inibição da doença, seja de forma curativa, quando as lagartas receberam a mistura da bactéria com a quitosana, seja preventivamente, oferecendo o produto às lagartas e, depois, inoculando-as com a bactéria (Li et al., 2010). 
Também, testaram-se in vitro extratos da alga Turbinaria conoides, com conhecidas propriedades antifúngicas, no desenvolvimento do fungo $B$. bassiana, sendo observado o efeito inibitório sobre o fungo. Em seguida, estudos in vivo também foram conduzidos com lagartas de B. mori, pela infecçáo prévia das lagartas com $B$. bassiana e posterior aplicaçáo do extrato de algas, conferindo de 75 a $85 \%$ de redução da mortalidade pelo patógeno (Kumari et al., 2011).

Ademais, há um estudo em que extrato pirolenhoso obtido de ramos de amoreira foi avaliado in vitro no desenvolvimento de $B$. bassiana e também sobre a cama de criação de $B$. mori. Segundo os autores, houve diminuição da incidência da doença e não se viu alteração nos parâmetros de produção de seda (MATsuki et al., 1998).

\section{CONSIDERAÇÕES FINAIS}

As perdas na sericicultura decorrentes de problemas associados a entomopatógenos são uma realidade enfrentada em todos os países produtores do bicho-da-seda. Ainda que existam protocolos de desinfecção dos barracóes, a contaminação persiste e não há métodos que garantam total proteção às lagartas. Portanto, considerando a necessidade de alternativas seguras e eficientes para o controle de doenças nas criaçóes comerciais de $B$. mori, ainda se têm poucos trabalhos perante a quantidade de produtos naturais ou alternativas que sejam seguros aos insetos e com reconhecidamente ação antimicrobiana. REFERÊNCIAS

ALVES, S.B. Fungos entomopatogênicos. In: ALVES, S.B. Controle microbiano de insetos. 2nd.ed. Piracicaba: FEALQ, 1998. p.289-370. Cap. 11.

AMARAL, E.; ALVES, S.B. Insetos úteis. Piracicaba: Livroceres, 1979. 188p.

BING, L.; YANHONG, W.; HAITAO, L.; YAXIANG, X.; ZHENGGUO, W.; YUHUA, C.; WEIDE, S. Resistance comparison of domesticated silkworm (Bombyx mori L.) and wild silkworm (Bombyx mandarina M.) to phoxim insecticide. African Journal of Biotechnology, Nigéria, v.9, n.12, p.1771-1775, 2010.

BIZHANNIA, A.R.; ETEBARI, K.; MATINDOOST, L. Bio-economic changes due to long time treatment of Carbendazim on Mulberry Silkworm (Bombyx mori L.) Caspian Journal of Environmental Sciences, Resht, v.3, n.1, p.23-27, 2005.

BRANCALHÃO, R.M.C. Vírus entomopatogênicos no bicho-da-seda. Biotecnologia: Ciência e Desenvolvimento, Brasília, n.24, p.54-58, 2002.

BRANCALHÃO, R.M.C.; RIBEIRO, L.F.C.; TORQUATO, E.F.B.; FERNANDEZ, M.A.; MUNHOZ, R.E.F.; COLOMBELLI, K.T.; COSTA, T.R.G. Avaliação antiviral do formulado de sódio dicloroisocianurato contra o nucleopoliedrovírus do bicho-da-seda. Arquivos do Instituto Biológico, São Paulo, v.80, n.2, p.233-235, 2013.

BRANCALHÃO, R.M.C.; TORQUATO, E.F.B.; CASTRO, M.E.B. Identificação de um isolado de Bombyx mori multiple nucleopolyhedrovirus (BmMNPV) no estado do Paraná, Brasil. Brasília: Embrapa, 2002. (Boletim de Pesquisa e Desenvolvimento, n.33).

CHAVAN, J.A.; PATIL, S.J.; BHAWANE, G.P. Screening of aqueous plant extracts against Beauveria bassiana infection to 5 th instar larvae of Bombyx mori L. Journal of Medicinal Plants Research, Maryland, v.5, n.16, p.3936-3939, 2011.
CORDOVA, D.; BENNER, E.A.; SACHER, M.D.; RAUH, J.J.; SOPA, J.S.; LAHM, G.P.; SELBY, T.P.; STEVENSON, T.M.; FLEXNER, L.; GUTTERIDGE, S. Anthranilic diamides: a new class of insecticides with a novel mode of action, ryanodine receptor activation. Pesticide Biochemistry and Physiology, Filadélfia, v.84, n.3, p.196-214, 2006. DOI: 10.1016/j.pestbp.2005.07.005

CORRADELLO, E.F.A. Bicho-da-seda e amoreira: da folha ao fio a trama de um segredo milenar. São Paulo: Ícone, 1987. $101 \mathrm{p}$.

CORSO, L.C.; MOSCARDI, F. Teste de fungicidas para o controle da incidência do fungo Beauveria sp. em Bombyx mori (Linnaeus, 1758). Anais da Sociedade Entomológica do Brasil, Londrina, v.10, n.1, p.129-133, 1981.

ESTADO DO PARANÁ; SECRETARIA DA AGRICULTURA E DO ABASTECIMENTO (SEAB); DEPARTAMENTO DE ECONOMIA RURAL (DERAL). Sericultura no estado do Paraná. Safra 2012/13 - Relatório Takii. 2013. Disponível em: <http://www.agricultura.pr.gov.br/arquivos/File/deral/ Prognosticos/Sericicultura_2012_13.pdf >. Acesso em: 10 fev. 2013.

FORMENTINI, M.A.; MAMPRIM, A.P.; MARTINELO, L.; RODRIGUES, E.; MARCHESE, L.P.C.; THOMAZONI, D.; ALVES, L.F.A. Efeito in vitro de produtos fitossanitários alternativos sobre Metarhizium anisopliae. Revista Brasileira de Agroecologia, v.4, n.2, 2009. Trabalho apresentado no Congresso Brasileiro de Agroecologia, 2009.

GALLO, D.; NAKANO, O.; SILVEIRA NETO, S.; CARVALHO, R.P.L.; BAPTISTA, G.C.; BERTI FILHO, E.; PARRA, J.R.P.; ZUCCHI, A.; ALVES, S.B.; VENDRAMIM, J.D.; MARCHINI, L.C.; LOPES, J.R.S.; ОMOTO, C. Entomologia agrícola. Piracicaba: Fealq, 2002.

GAMA GASES. Propriedades dos gases: cloro. 2007. Disponível em: <http://www.gamagases.com.br/propriedades_cloro.htm>. Acesso em: 20 mar. 2014. 
HANADA, Y.; WATANABE, J.K. Manual de criação do bicho-da-seda Curitiba: Cocamar, 1986. 224p.

HUSSAIN, M.; NAEEM, M.; KHAN, S.A.; BHATTI, M.F.; MUNAWAR, M. Studies on the influence of temperature and humidity on biological traits of silkworm (Bombyx mori L.; Bombycidae). African Journal of Biotechnology, Abraka, v.10, n.57, p.12368-12375, 2011.

INTERNATIONAL SERICULTURAL COMMISSION. Statistics: global silk industry. 2013. Disponível em: <http://inserco.org/en/ statistics>. Acesso em: 15 maio 2014.

ISAIARASU, L.; SAKTHIVEL, N.; RAVIKUMAR, J.; SAMUTHIRAVELU, $P$. Effect of herbal extracts on the microbial pathogens causing flacherie and muscardine diseases in the mulberry silkworm, Bombyx mori L. Journal of Biopesticides, Tamil Nadu, v.4, n.2, p.150-155, 2011.

KUMAR, K.P.K.; SINHA, A.K.; SINGH, G.P.; MADHUSUDHAN, K.N. Efficacy of systemic fungicides for control of white muscardine in tasar silkworm, Antheraea mylitta D. Research Journal of Microbiology, v.6, n. 1 1, p.805-812, 201 1. DOI: 10.3923/jm.2011.805.812

KUMAR, V.; SINGH, G.P.; BABU, A.M.; AHSAN, M.M.; DATTA, R.K. Germination, penetration, and invasion of Beauveria bassiana on silkworm, Bombyx mori, causing white muscardine. Italian Journal of Zoology, Roma, v.66, n.1, p.39-43, 1999. DOI: 10.1080/11250009909356235

KUMARI, S.S.; RAO, S.V.S.; MISRA, S.; MURTY, U.S. Antifungal activity of Turbinaria conoides and evaluation for the effective concentration against the infection of Beauveria bassiana in silkworm larvae. Research Journal of Microbiology, Índia, v.6, n.2, p.115-123, 2011 . DOI: 10.3923/jm.2011.115.123

KURIN, R. The silk road: the making of a global cultural economy. Anthronotes, Washington, D.C., v.23, n. 1, 2002.

LI, B.; SU, T.; CHEN, X.; LIU, B.; ZHU, B.; FANG, Y.; QIU, W.; XIE, G. Effect of chitosan solution on the bacterial septicemia disease of Bombyx mori (Lepidoptera: Bombycidae) caused by Serratia marcescens. Applied Entomology and Zoology, Tokyo, v.45, n. 1 , p.145-152, 2010. DOI: 10.1303/aez.2010.145

LÓPEZ, N.J.C.; BUSTILLO, P.A.E. Evaluación de tres fungicidas para la prevención de la muscardina blanca y su efecto en el desarrollo del gusano de seda Bombyx mori L. In: CONGRESO DE LA SOCIEDAD COLOMBIANA DE ENTOMOLOGÍA, 1993, Colômbia. Resumos. Cali, Colômbia: 1993. p.69.

MAMPRIM, A.P.; ALVES, LF.A.; PINTO, F.G.S.; FORMENTINI, M.A.;MARTINS, C.C.; PARES, R.B. Effect of phytosanitary products on biological parameters of Beauveria bassiana (Bals.) Vuill. (Hypocreales: Cordycipitaceae). Revista de Protección Vegetal, Havana, v.29, n.2, p.128-136, 2014.

MARGATHO, L.F.F.; OKAMOTO, F.; ALMEIDA, A.M.; SANTOS, C.A.J.P. Avaliação quantitativa da contaminação por microorganismos no ambiente de criação do bicho-da-seda (Bombyx mori L.) na fase de chocadeira. Arquivos do Instituto Biológico, São Paulo, v.79, n.2, p.233-238, 2012.

MATSUKI, N.; MITAMURA, T.; DOI, N. Effect of wood vinegar to fungus disease of silkworm, Bombyx mori. Journal of Sericulture
Science of Japan, v.67, n.2, p.143-145, 1998. DOI: 10.11416/ kontyushigen 1930.67.143

MERTZ, N.R.; ALVES, L.F.A.; MARCOMINI, A.; OLIVEIRA, D.G.P.; SANTOS, J.C. Efeito de produtos fitossanitários naturais sobre Beauveria bassiana (Bals.) Vuill. in vitro. BioAssay, Piracicaba, v.5, n.3, p.1-10, 2010. DOI: 10.14295/BA.v5.0.71

MOHANAN, N.M.; GRUPTA, S.K.; MITRA, P. Antimycotic activity of Allium sativum against Beauveria bassiana, pathogenic fungus of white muscardine disease in silkworm, Bombyx mori L. (Lepidoptera: Bombycidae). International Journal of Industrial Entomology, Seul, v.14, n.2, p.81-85, 2007.

MUNHOZ, R.E.F.; MIZUNO, S.; AITA, W.S.; BIGNOTTO, T.S.; PEREIRA, N.C.; SAEZ, C.R.N.; BESPALHUK, R.; FASSINA, V.A.; PESSINI, G.M.; RANDO, F.S.; RIBEIRO, L.F.C.; BRANCALHÃO, R.M.C.; FERNANDEZ, M.A. Efeito do inseticida Chlorantraniliprole sobre a produtividade de bicho-da-seda. In: SIMPÓSIO DE CIÊNCIAS APLICADAS A SERICICULTURA, 3., 2012, Maringá.

NASR, H.M. Toxicological and biochemical effects of chlorpyrifos, chlorfluazuron na oxymatrine on larvae of Bombyx mori. Journal of Agricultural Research, Lahore, v.37, n.1, p.209-221, 2011.

NATARAJU, B.; CHANDRASEKHARAN, K. Studies on white muscardine disease of mulberry silkworm Bombyx mori $\mathrm{L}$. in India: a review. Indian Journal of Sericulture, Mysore, v.47, n.2, p. $136-154,2008$.

PARES, R.B. Controle e prevenção da calcinose branca em Bombyx mori L. (Lepidoptera: Bombycidae) por produtos fitossanitários alternativos. 2014. $41 \mathrm{f}$. Trabalho de conclusão de curso (Graduação em Ciências Biológicas) - Universidade Estadual do Oeste do Paraná, Cascavel, 2014

PARRA, J.R.P. Consumo e utilização de alimentos por insetos. In: PANIZZI, A.R.; PARRA, J.R.P. (Orgs.). Ecologia nutricional de insetos e suas implicações no manejo de pragas. São Paulo: Manole Saúde, 1991.

PEREIRA, N.C.; MIZUNO, S.; AITA, W.S.; MUNHOZ, R.E.F.; BIGNOTTO, T.S.; SAEZ, C.R.N.; BESPALHUK, R., FASSINA, V.A.; PESSINI, G.M.; RIBEIRO, L.F.C.; BRANCALHÃO, R.M.C.; COLOMBELLI, K.T.; FERNANDEZ, M.A. Concentração letal e sintomatologia da intoxicação pelo inseticida Chlorantraniliprole em lagartas de Bombyx mori. In: SIMPÓSIO DE CIÊNCIAS APLICADAS À SERICICULTURA, 2012, 3., Maringá.

PORTO, A.J.; OKAMOTO, F. Efeito da aplicação de desinfetante sobre o bicho-da-seda (Bombyx mori L.). Boletim da Indústria Animal, Nova Odessa, v.57, n.2, p.193-199, 2000.

PORTO, A.J.; OKAMOTO, F.; IKUNO, A.A.; FERREIRA, V.C.A.; MARGATHO, L.F.A. Avaliação biológica e produtiva do bicho-da-seda (Bombyx mori L.) alimentado com folhas de amoreira pulverizadas com extrato de Mirabilis jalapa. Arquivos do Instituto Biológico, São Paulo, v.72, n.4, p.445-453, 2005.

POTRICH, M.; ALVES, L.F.A.; BRANCALHÃO, R.C.; DALCIN, G. Entomopatógenos associados a lagartas de Bombyx mori $\mathrm{L}$. (Lepidoptera: Bombycidae) no estado do Paraná. Arquivos do Instituto Biológico, São Paulo, v.74, n.4, p.363-367, 2007. 
RAJAGOPAL, V.; RAMESH, H.L.; YOGANANDA MURTHY, V.N.; NINGE GOWDA, K.N. Efficacy of fungicide "Kavach" against Beauveria bassiana L. in silkworm Bombyx mori L. Journal of Applied and Natural Science, Chennai, v.6, n.1, p.31-37, 2014.

SECRETARIA DA AGRICULTURA E DO ABASTECIMENTO. Origem da sericicultura. 2005. Disponível em: <http://www.agricultura. pr.gov.br/arquivos/File/complexo_da_seda/folder_origem.pdf $>$. Acesso em: 14 ago. 2013.

SELVAKUMAR, T.; NATARAJU, B.; BALAVENKATASUBBAIAH, M.; SIVAPRASAD, V.; BAIG, M. A report on the prevalence of silkworm diseases and estimated crop loss. Advances in Indian Sericulture Research, Mysore, p.354-357, 2002.

SUPERQUÍMICA. Ficha de informações de segurança de produtos químicos: cal hidratada. 2010. Disponível em: < http://www.superquimica.com. br/fispq/1323458630.pdf>. Acesso em: 20 mar. 2014.

SUPERQUÍMICA. Ficha de informações de segurança de produtos químicos: formol. 2011 . Disponível em: < http://www.superquimica. com.br/fispq/1299157852.pdf>. Acesso em: 10 fev. 2014.

SURENDRA, N.B. \& SURENDRA, K.R.P. Toxic impact of organophosphorus inseticides on acetylcholinesterase activity in the silkworm, Bombyx mori L. Ecotoxicology and Environmental Safety, v.42, n.2, p.157-162, 1999. DOI: 10.1006/eesa.1998.1735

TORQUATO, E.F.B.; MIRANDA NETO, M.H.; BRANCALHÃO, R.M.C.; FRANCO, V.S. Nucleopolyhedrovirus: scanning electron microscopy technique. Neotropical Entomology, Londrina, v.35, n.6, p.787-790, 2006. DOI: 10.1590/ S1519-566X2006000600011

VALE DA SEDA. Produção de seda no Brasil. 2010. Disponível em: <http://www.valedaseda.org.br/?page=historico/>. Acesso em: 26 maio 2013.

ZANETTI, R. Notas de aula de Entomologia: sericicultura. Bicho-da-seda. Lavras: DEN/UFLA, 2011 a. Disponível em <http:// www.den.ufla.br/siteantigo/Professores/Ronald/Disciplinas/ Notas\%20Aula/Sericicultura\%2Obichodaseda.pdf > Acesso em: 13 fev. 2014.

ZANETTI, R. Notas de aula de Entomologia: sericicultura. Manejo e criação do bicho-da-seda. Lavras: DEN/ UFLA, 2011 b. Disponível em: <http://www.den.ufla.br/ siteantigo/Professores/Ronald/Disciplinas/Notas\%20 Aula/Sericicultura\%20bichodaseda.pdf $>$. Acesso em: 26 maio 2013 